\title{
Psychogenic Stuttering Following a Gastric Bypass Operation: Case Report
}

\author{
Deborah B. Raphael M.D. (PGY2) \\ draphael@lppi.ucsf.edu
}

Frank B. Schoenfeld M.D.

Follow this and additional works at: https://jdc.jefferson.edu/jeffjpsychiatry

Part of the Psychiatry Commons

Let us know how access to this document benefits you

\section{Recommended Citation}

Raphael, Deborah B. M.D. (PGY2) and Schoenfeld, Frank B. M.D. (2006) "Psychogenic Stuttering Following a Gastric Bypass Operation: Case Report," Jefferson Journal of Psychiatry. Vol. 20 : Iss. 1 , Article 3.

DOI: https://doi.org/10.29046/JJP.020.1.002

Available at: https://jdc.jefferson.edu/jeffjpsychiatry/vol20/iss $1 / 3$

This Article is brought to you for free and open access by the Jefferson Digital Commons. The Jefferson Digital Commons is a service of Thomas Jefferson University's Center for Teaching and Learning (CTL). The Commons is a showcase for Jefferson books and journals, peer-reviewed scholarly publications, unique historical collections from the University archives, and teaching tools. The Jefferson Digital Commons allows researchers and interested readers anywhere in the world to learn about and keep up to date with Jefferson scholarship. This article has been accepted for inclusion in Jefferson Journal of Psychiatry by an authorized administrator of the Jefferson Digital Commons. For more information, please contact: JeffersonDigitalCommons@jefferson.edu. 


\section{Psychogenic Stuttering Following a Gastric Bypass Operation: Case Report}

Deborah B. Raphael, M.D. (PGY2), Frank B. Schoenfeld, M.D.

\section{ABSTRACT}

We evaluated a 44-year-old female with bipolar affective disorder who presented with a 4-month history of severe stuttering and vague neurologic complaints. She had lost 200 pounds after gastric bypass surgery two years before. A childhood sexual- abuse victim, she admits that she "hid" in her weight for most of her life. Neurological evaluation of this patient was negative, and speech-pathology evaluation revealed highly atypical stuttering. Gastric bypass patients with a history of psychiatric disorders and childhood sexual abuse may be particularly vulnerable to somatoform disorders.

It has been widely reported that psychological complications are prevalent among the morbidly obese, although this point has been controversial (1). Glinski et al. elucidated that $70 \%$ of patients evaluated for gastric bypass surgery meet criteria for an Axis I disorder in the past or present and 36\% for Axis II disorder (2). In his study, he found that the lifetime prevalence of depressive disorders alone in this population was 56\%, compared with the known lifetime prevalence of depressive disorders of about $17 \%$ in the general population. Glinski noted that gastric bypass surgical candidates tend to use denial as a defense mechanism for avoiding negative emotions. In keeping with this, overeating may serve as distraction from negative emotion in these individuals. Somatization is another tendency in this particular population.

Some improvement of psychosocial functioning after surgical treatment of obesity has been reported (3). Van Gemert et al. recently investigated the longterm effects of surgically induced weight loss on the psychological functioning of morbidly obese patients. They found that preoperative subjects had elevated values on negativism, somatization, and shyness scales on personality profiles; postoperatively, all these values normalized except somatization. Thus, postoperative patients still were concerned about their health and still were inclined to react to psychological stress with physical complaints. 
Interestingly, Waters et al. found that the dramatic improvement in those mental health indices observed 6 and 12 months after gastric bypass surgery tends to erode to preoperative values two years after surgery, despite no weight gain (4). As a possible explanation for this psychological regression, Waters's group noted that for the first 12 postoperative months, patients have frequent clinic visits that taper off over the second year: continued psychological support may remain essential for patients after bariatric surgery. Moreover, patients with previously diagnosed Axis I disorders may require more support than those without. When Halmi et al. evaluated 80 morbidly obese patients after gastric bypass, they found that those patients with documented psychiatric diagnoses had a significantly greater amount of psychosocial stress than those without those diagnoses (1).

\section{Impact of Past Sexual Abuse on Obesity and Outcome after Gastric Bypass}

Sexually abused women are more likely than nonabused women to receive a psychiatric diagnosis during their lifetimes (5). Women with a history of sexual abuse are also more likely to experience somatically based stress disorders and somatic disorders in general (6). Moreover, multiple studies have found a relationship between childhood sexual abuse and extreme obesity. Associations between childhood physical abuse and obesity, as well as between childhood neglect and obesity, also have been found (7), but core psychological reasons may differ.

A chart review of 131 patients by Gustafson et al. revealed that $60 \%$ of those who reported a history of sexual abuse were more than 50 pounds overweight, compared with $28 \%$ of age-and-sex-matched patients without a history of sexual abuse (5). In addition, 25\% of the abused group was found to be more than 100 pounds overweight, compared with only $6 \%$ of controls. Researchers have proposed that the obesity may serve as protection from sexual advances from potential abusers. Wiederman et al. showed that among obese women, those with a history of sexual abuse reported less body dissatisfaction and less weight fluctuation during adulthood compared with obese women who were not sexually abused, indicating that excess weight likely serves a particular function in sexual abuse victims (8). Moreover, King, et al found in an outpatient weightmanagement program that research subjects with a history of sexual abuse lost significantly less weight than those with no history of abuse (9). It has been suggested that weight reduction in these patients may trigger anxiety symptoms as women approach the weight at which they were abused $(5,9)$.

Researchers have examined the correlation between sexual abuse history and weight-loss treatment failure. In general, childhood sexual abuse survivors are less likely to be successful in maintaining weight loss after obesity treatment (10). 
King et al. showed that obese individuals with a history of sexual abuse were more likely to have experienced psychological distress and to have lower self efficacy than their counterparts who were not abused, making compliance with an obesity treatment program exceedingly difficult in comparison. It follows that a history of sexual abuse is an important pretreatment variable that may have a significant impact on obesity treatment outcome (9). Although Buser et al. showed in their study that females with a history of sexual abuse were as successful with weight loss for the first 14 months after gastric bypass surgery as those without a history of sexual abuse, they do validate the necessity of additional support during and after weight loss interventions for individuals with a history of sexual abuse (11).

\section{Psychogenic stuttering}

Stuttering is generally categorized as developmental or acquired. Adult-onset stuttering is either a reemergence of a childhood (developmental) stutter or acquired, either neurogenic or psychogenic in nature. The mechanism of developmental stuttering still is not well-understood: impaired neuronal communication, disturbed timing of activation in speech-relevant brain areas, and neuroanatomical abnormalities in the speech-language areas all have been implicated $(12,13)$. Neurogenic causes of acquired stuttering include head injury, stroke, degenerative disease of the central nervous system, brain tumor, brainsurgery, defects in the basal nuclei or thalamus, and drug-induced brain dysfunctions $(14,15)$. In a case series by Roth, et al. involving 12 subjects with adult-onset stuttering that turned out to be psychogenic in nature, all initially required differentiation of neurologic from psychogenic stuttering through interdisciplinary collaboration. All 12 subjects with psychogenic stuttering presented with other, concomitant neurologic-like complaints which also turned out to be nonorganic in etiology (16).

Psychogenic stuttering is well-described (15). The term "conversion reaction," which refers to a process, through which psychological stress is converted into a somatic symptom, largely has replaced the older term "hysteria." Psychogenic stuttering, once known as "hysterical stuttering," currently is considered a conversion disorder: an alteration in physical functioning that suggests a physical disorder but is an expression of psychological conflict (15).

The sudden onset of psychogenic stuttering is commonly preceded by an emotionally traumatizing event. Ten of the twelve patients that comprised Roth's aforementioned case series had significant psychological disturbances surrounding the onset and development of the stuttering; the remaining two subjects were equivocal in this regard (16). Mahr and Leith recently described a woman with an abuse history who was struggling with her decision to leave her husband when she 
suddenly began to stutter (15). Deal has suggested that adult-onset nondevelopmental and non-neurologically based stuttering usually has a sudden onset and is temporally linked to some form of psychological trauma or cumulative psychological stress (17). He reported an adult patient who had two discrete episodes of sudden-onset stuttering, each after an unsuccessful suicide attempt.

Mahr and Leith have presented a clear synthesis of the most up-to-date diagnostic schemes for psychogenic stuttering. Defining criteria 1. a change in speech pattern suggesting stut-tering; 2 . a relationship to psychological factors; 3. absence of organic cause. Associated symptoms 1. history of mental illness; 2. atypical features of stuttering, such as no secondary symptoms and no islands of fluency; 3. la belle indifference. These authors have proposed that for stuttering to be diagnosed as a conversion reaction, all defining criteria must be met in addition to one associated symptom (15).

As opposed to developmental stuttering, for which studies have demonstrated a 1:3 female:male ratio, psychogenic stuttering has been shown to occur in a 1:1 female: male ratio (14).

\section{CASE REPORT}

Ms. S is a 44-year-old Caucasian female who, two years after Roux-en-Y gastric bypass for morbid obesity, presented to us with a 4-month history of severe stuttering. Neurologic symptoms were present also, which had been intermittent over the last year but worse over the last four months. As a result of symptoms, she had stopped working. Bipolar affective disorder had been diagnosed 15 years earlier, and, in addition, she reported childhood sexual abuse.

Ms. S has been hospitalized several times for bipolar illness. One admission was for feeling "low" after separation from her first husband; another was for adjustment of her psychiatric medications. Lithium had caused a "toxic reaction," valproic acid gave her "decreased touch sensation," then carbamazepine was started without adverse effect. More recently, low dose quetiapine was also initiated. Of note, stuttering began prior to the initiation of quetiapine. This patient has no history of substance abuse.

Past medical history is significant for obesity, which worsened after the births of her three children in her early twenties. Tubal ligation was carried out in her late twenties. The gastric bypass-operation mentioned above was accompanied by open cholecystectomy. 
Ms. S was thin as a child, but gained weight at puberty: she was afraid to be around boys, and her developing body triggered memories of sexual abuse at age three by her father. In her adolescence she avoided boys and tried to "hide" in her weight. "A lot of therapy" over the years helped her deal with her childhood sexual abuse until she reached a point where she no longer psychologically "needed" the weight.

She has a Bachelor's Degree, has completed graduate-level coursework, and has been employed in the field of career-development. She married in her early twenties and felt supported by her husband, although the intimate nature of their relationship was limited. Her three children, with whom she has a close relationship, are from this marriage. After 20 years of marriage, Ms. S and her first husband divorced, owing to his involvement with other women. Following the divorce, Ms. S proceeded with gastric bypass, which resulted in a loss of 200 pounds. Over the next year, she found herself to enjoy dating, which involved physical intimacy with men. About one year ago, she married her current husband, whom she describes as supportive, and with whom she is frequently physically intimate. She does report that her new husband has told her that he likely would not have taken interest in her had she been overweight when they first met.

Two siblings suffer from a mood disorder and from substance abuse; alcoholism has been present in both parents. Her father died from a brain tumor, and her grandfather had Parkinson's disease.

She is pleasant and friendly, stuttering on many of her words. She does not "mind the stuttering" and says with a smile that she "would not want to associate with people who would take issue with it anyway." She reports an active social life and has been initiating conversation with new people without selfconsciousness. Her "flippers," which she calls her minimal bilateral arm fat, seem to be of more concern to her than is the stuttering. However, she does report that stuttering and occasional double vision interfere with her ability to work because she could not answer phones effectively or drive safely. As she describes matters, she has become highly dependent on her husband and her children to drive her to numerous medical appointments that now occupy much of her time.

Affect is labile during interviews; she is tearful when speaking about her bipolar disorder and the inability of medications to "fix it." Throughout her life, she has felt that care providers have not believed her regarding her mood symptoms. This has frustrated her; she compares it to times in her childhood when her mother would not believe she was sick unless there was objective evidence, such as a fever. The patient cites low self-esteem as her biggest lifelong psychological problem, often feeling that she is "a bother" to people, particularly when she has depressed mood. She worries that her new husband may leave her, and she fears 
gaining weight because "looks" are very important to him. Even so, things have been going well in the last year: a generally supportive marriage and a rewarding, albeit stressful, job. Ms. S has been told that her stuttering may be related to "anxiety," but is confused because stress level has been much higher in other times of her life. Stuttering has never existed in the past. Moreover, she asserts, the only person she has ever known who stuttered is a character on a television program that she used to watch often.

She is unable to recount the details around the sudden onset of stuttering, but recalls that it started at the end of a vacation with her husband about one month prior to termination with her therapist of eight years; the latter was moving across the country. Ms. S now states that were she to stop stuttering, she might "miss it," because it has become part of her "identity." She does not believe that she has received more attention since the stuttering began. She has stopped working, going on disability and enjoying her new status as a "domestic engineer."

Extensive neurological workup was carried out for the following complaints: stuttering, continuous for 4 months, of sudden onset; double vision, about 20 percent of the time, for 4 months; hand tremor, at rest, for one week; and memory and attention difficulties over the past month. Tremor was not observed during serial physical examinations, and unsteadiness with tandem gait and difficulty with balance were present on some occasions but not others; finger-nose-finger and heel-to-shin exercises were within normal limits. In sum, physical findings were inconsistent and elaborated. A thorough ophthalmic evaluation showed no abnormalities. MRA and MRI imaging was unremarkable, and testing was negative for infectious, endocrinologic, metabolic, and rheumatologic processes.

Speech evaluation revealed a moderate to severe dysfluency in about 50 percent of all spoken words, persisting when reading slowly. Certain behaviors were missing that normally accompany dysfluencies in adults: prolongations of sounds and secondary mannerisms (increased facial muscle or laryngeal tension). Neither discontinuation of quetiapine nor reduction in the dose of carabamazepine improved the patient's symptoms.

When the symptoms initially arose, Ms. S had begun to schedule more medical and psychiatry appointments; this was shortly before termination with her therapist of eight years. Since, she has seen psychiatrists at more than one facility and has sought multiple primary care visits. Chief complaints vary; one such is that of urinary symptoms (but they are unaccompanied by evidence of infection). Weekly psychotherapy sessions were initiated at our institution, but her care soon was transferred to a facility closer to her home. 


\section{DISCUSSION}

Neurologic complications of bariatric surgical procedures do occur, neuropathy, encephalopathy, vitamin B12 deficiency, and thiamine deficiency, for example (18). Although we found no evidence of an organic basis for our patient's symptoms, we did find from speech and psychological evaluations that, in addition to la belle indifference, nearly every criterion (see above) of Mahr and Leith for psychogenic stuttering was present. And multiple and vague quasi-neurologic symptoms accompanied the complaint of stuttering, just as Roth observed in all twelve of his psychogenic-stuttering subjects (16).

Accepting the diagnosis of a conversion reaction in this patient, what unconscious psychological conflict does Ms. S express through her stuttering? A number of possibilities exist. A therapist of eight years recently moved away. This abrupt termination took place alongside the recent, steady diminution of this patient's medical appointments since the bariatric operation, cutting her contact with care providers significantly. As mentioned, Waters has noted an erosion of mental health about two years after gastric bypass surgery (4). This also is when some patients tend to regain weight. Ms. S fears gaining weight because she worries that her husband will leave her if she becomes obese. On the other hand, as a sexual abuse survivor, without the protection of obesity she may be especially vulnerable to unconscious fear (9). Somatic symptoms produce the nurturing care, the protection, of family and healthcare workers. She can cite many instances in her life when she has tried to communicate her needs and has not been believed; stuttering is noticeable; it demands attention. And, given the involvement of the oral cavity in stuttering, one might wonder if the symptom represents a displacement of guilt or fantasy about either oral sex or eating. These would be topics to further explore in dynamically oriented psychotherapy.

Could the emergence of Ms. S's somatic symptoms have been prevented? A history existed of both bipolar affective disorder and childhood sexual abuse: one could argue that she was predisposed to psychological deterioration after her identity-altering surgery. According to both Waters and Buser, additional and continued psychological support should be offered to patients following bariatric operations, particularly those with a history of a psychiatric disorder and a history of childhood sexual abuse $(4,11)$. 


\section{SOURCE INFORMATION}

From the Department of Psychiatry, University of California, San Francisco (D.B.R.) and the Department of Veterans Affairs Medical Center, San Francisco (F.B.S.). The authors thank John Devine, M.D. and Victoria Tichenor, Ph.D. for their clinical supervision for this case. Identifying details have been changed to protect patient confidentiality. Direct inquires to Dr. Raphael at DRaphael@lppi.ucsf.edu

\section{REFERENCES}

1. Halmi KA, Long M, Stunkard AJ, Mason E. Psychiatric diagnosis of morbidly obese gastric bypass patients. Am J Psychiatry 1980; 137:470-2

2. Glinski J, Wetzler S, Goodman E. The psychology of gastric bypass surgery. Obes Surg 2001; 11:581-8

3. van Gemert WG, Severeijns RM, Greve JW, Groenman N, Soeters PB. Psychological functioning of morbidly obese patients after surgical treatment. Int J Obes Relat Metab Disord 1998; 22:393-8

4. Waters GS, Pories WJ, Swanson MS, Meelheim HD, Flickinger EG, May HJ. Long-term studies of mental health after the Greenville gastric bypass operation for morbid obesity. Am J Surg 1991; 161:154-8

5. Gustafson TB, Sarwer DB. Childhood sexual abuse and obesity. Obes Rev 2004; 5:129-35

6. Bryer JB, Nelson BA, Miller JB, Krol PA. Childhood sexual and physical abuse as factors in adult psychiatric illness. Am J Psychiatry 1987; 144:1426-30

7. Williamson DF, Thompson TJ, Anda RF, Dietz WH, Felitti V. Body weight and obesity in adults and self-reported abuse in childhood. Int J Obes Relat Metab Disord 2002; 26:1075-82

8. Wiederman MW, Sansone RA, Sansone LA. Obesity among sexually abused women: an adaptive function for some? Women Health 1999; 29:89-100

9. King TK, Clark MM, Pera V. History of sexual abuse and obesity treatment outcome. Addict Behav 1996; 21:283-90 
10. Romans SE, Martin JL, Morris E, Herbison GP. Psychological defense styles in women who report childhood sexual abuse: a controlled community study. Am J Psychiatry 1999; 156:1080-5

11. Buser A, Dymek-Valentine M, Hilburger J, Alverdy J. Outcome following gastric bypass surgery: impact of past sexual abuse. Obes Surg 2004; 14:170-4

12. Packman A, Onslow M. Searching for the cause of stuttering. Lancet 2002; 360:655-6

13. Sommer M, Koch MA, Paulus W, Weiller C, Buchel C. Disconnection of speech-relevant brain areas in persistent developmental stuttering. Lancet 2002; 360:380-3

14. Vossler DG, Haltiner AM, Schepp SK, Friel PA. Caylor LM. Morgan JD. Doherty MJ. Ictal stuttering: a sign suggestive of psychogenic nonepileptic seizures. Neurology 2004; 63:516-9

15. Mahr G, Leith W. Psychogenic stuttering of adult onset. J Speech Hear Res 1992; 35:283-6

16. Roth CR, Aronson AE, Davis LJ Jr. Clinical studies in psychogenic stuttering of adult onset. J Speech Hear Disord 1989; 54:634-46

17. Deal JL. Sudden onset of stuttering: a case report. J Speech Hear Disord 1982; 47:301-4

18. Koffman BM, Greenfield LJ, Ali, II, Pirzada NA. Neurologic complications after surgery for obesity. Muscle Nerve 2006; 33:166-76 